\title{
NEBIVOLOL AMELIORATES INDOMETHACIN-INDUCED GASTRIC ULCER IN ADULT ALBINO RATS: ROLE OF INDUCIBLE NITRIC OXIDE SYNTHASE
}

\author{
Omaima M. Abd Allah* and Abeer A. I. Sharaf El-Din ** \\ *Department of Pharmacology and Therapeutics, ${ }^{* *}$ Department of Forensic Medicine and \\ Toxicology, Faculty of Medicine, Benha University
}

\begin{abstract}
The effect of nebivolol (NBV), a third-generation selective $\beta 1$ - antagonist, on indomethacin (IND) - induced gastric ulcer in rats was investigated. Thirty two male rats were used in this study, divided into four groups as follows: control group, IND ulcer-induced group, IND + NBV ( $1 \mathrm{mg} / \mathrm{kg} /$ day, p.o.) group, and IND + NBV $(5 \mathrm{mg} / \mathrm{kg} /$ day, p.o.) group. Gastric ulcer was induced by a single injection of IND (30 $\mathrm{mg} / \mathrm{Kg}$, i.p.); NBV was administered for seven days prior to ulcer induction. At the end of the experiment, the stomach of each rat was removed for macroscopic examination and gastric ulcer scoring. The gastric mucosa was prepared for quantitative real-time polymerase chain reaction (qRT-PCR) and tissue homogenate preparation for biochemical study. Then, the remaining part was used for histopathological and immunohistochemical examination. Results showed that NBV significantly protected rats from indomethacin-induced gastric ulceration. There is a significant decreased in the mean ulcer number, score and index along with increased preventive index. Also, NBV significantly decreased the elevations of nitrite/nitrate, malondialdehyde, tumor necrosis factor- $\alpha$, and interleukin-1beta in IND-treated rats. In addition, NBV significantly ameliorated the IND-induced reductions of glutathione level, glutathione peroxidase, superoxide dismutase, and catalase activities, and prostaglandin $\mathrm{E}_{2}$. Moreover, histopathological, immunohistochemical analysis of inducible nitric oxide synthase (iNOS) and qRT-PCR for mRNA expression of iNOS gene:confirmed the biochemical results. It was concluded that NBV renders protection in IND-induced gastric ulceration in rats via maintenance of mucosal nitric oxide and prostaglandin $\mathrm{E}_{2}$, reducing oxidative stress and inflammatory responses.
\end{abstract}

Keywords: Indomethacin, nebivolol, gastric ulcer, rats.

\section{INTRODUCTION}

The nonsteroidal anti-inflammatory drugs (NSAIDs) are broadly prescribed for the treatment of pain and inflammation in rheumatic disorders and osteoarthritis. However, their therapeutic effects are complicated with gastrointestinal (GI) toxicity especially among the elderly and patients with a history of GI bleeding or complications (Wilcox, 2006). Hypertension affects the majority of people over 65 years of age, occurring in up to $60 \%$ of this population
(Bacic-Vrca et al., 2010). The frequent use of NSAIDs especially by older hypertensive populations who often experience chronic and acute pain, may contribute to the increased coexistence of hypertension and gastric ulcer. Antihypertensive drugs and NSAIDs are used concomitantly by at least $12-15 \%$ of older patients (Kalafutova et al., 2014). Therefore, the effect of different antihypertensive drugs should be investigated for their effect as gastroprotective agents. 
Indomethacin, a representative of NSAIDs family, causes gastric ulcers by various mechanisms, including depletion of endogenous prostaglandins via inhibition of cyclooxygenase enzyme (COX) (Simmons et al., 2004), increased mucosal production of proinflammatory cytokines (Koizumi et al., 2009), generation of oxygen free radicals and lipid peroxidation (Naito \& Yoshikawa, 2006), up-regulation of adhesion molecules, followed by adherence of neutrophils to the microvascular endothelium leading to generation of free radicals and tumor necrosis factor- alpha (TNF- $\alpha$ ) by activated neutrophils, and depletion in mucosal blood flow as possible cause of polymorphonuclear leukocyte infiltration to gastric mucosal tissue (Yadav et al., 2012). In addition, the reduction of constitutive nitric oxide synthase (cNOS) activity and over-expression of inducible nitric oxide synthase (iNOS) was reported to mediate the increased ulcerogenic response to indomethacin (Slomiany \& Slomiany, 2000; Maity et al., 2009).

The use of nitric oxide-modulating agents concomitantly with non-steroidal anti-inflammatory drugs as aspirin resulted in reduced risk for gastric ulceration and bleeding (Mourad et al., 2000). Nebivolol is a third-generation, long-acting and highly selective $\beta 1$ adrenergic receptor antagonist that also induces nitric oxide (NO)-mediated vasodilatation by stimulating endothelial NO synthase via $\beta 3$ agonism (Munzel \& Gori, 2009). It is currently FDAapproved for treatment of hypertension and has been evaluated for the treatment of chronic heart failure (Fongemie \& Felix- Getzik, 2015). Antioxidative, anti-inflammatory and anti-proliferative properties of nebivolol have been reported, contributing to additional value in the treatment of hypertension (Wehland et al., 2012).

\section{AIM OF THE WORK:}

These multiple beneficial effects of nebivolol may suggest its use as a gastroprotective agent. Hence, the aim of the present study was to evaluate the gastroprotective effects of nebivolol on gastric ulcer induced by indomethacin in rats, and to elucidate the mechanisms underlying these effects. In addition, the relation between nebivolol and expression of cytotoxic iNOS was also investigated.

\section{MATERIALS \& METHODS}

\section{Drugs:}

Indomethacin (IND) and nebivolol (NBV) were purchased from SigmaAldrich Chemical Co. (St Louis, MO, USA). IND was suspended in $1 \%$ aqueous solution of Tween 80 and NBV was suspended in $0.5 \%$ aqueous solution of carboxymethyl-cellulose (CMC). All drugs used in the study were freshly prepared and other chemicals used were of the high analytical grade.

\section{Animals:}

Adult male Wistar albino rats weighing between 180 and $200 \mathrm{~g}$ were used in the present study. The animals were purchased from Helwan farm (Holding Company for Biological Products and Vaccines, VACSERA, Egypt). The animals were housed in the animal facility of Faculty of Medicine, Benha University, Egypt, for one week before the onset of the experiment for atmospheric and handling accommodation. They kept individually in mesh-bottomed cages to minimize coprophagia which interferes with the induction of gastric ulcer. The animals were maintained under good hygienic 
and standard laboratory conditions $(12 \mathrm{~h}$ light/ dark cycles at $25 \pm 2{ }^{\circ} \mathrm{C}$ ), fed ad libitum and allowed for free water supply. Every effort was made to minimize the number of animals used and their suffering. All animal treatments comply strictly with institutional ethical guidelines of the care and use of laboratory animals. The experimental protocol was approved by ethical committee (Faculty of medicine, Benha University, Egypt).

\section{Animal grouping and experimental design:}

Animals $(\mathrm{n}=32)$ were divided into four equal groups. The first one served as control group in which animals received $0.5 \% \mathrm{CMC}$ orally (vehicle of NBV) for seven successive days. On the $7^{\text {th }}$ day of the study period, after $24 \mathrm{~h}$ of fasting, rats received single intraperitoneal injection of $1 \%$ aqueous solution of Tween 80 (vehicle of IND) one hour after the last CMC dose. The second group served as IND ulcerinduced group and received $0.5 \% \mathrm{CMC}$ orally for seven successive days. On the $7^{\text {th }}$ day of the study period, after $24 \mathrm{~h}$ of fasting, rats were subjected to gastric ulcer induction by a single dose of IND $30 \mathrm{mg} / \mathrm{kg}$, i.p. injection (one hour after the last CMC dose). The dose of IND was chosen according to the previous study by Khattab et al. (2001). The third and fourth groups were IND + NBV groups in which animals pretreated with NBV suspended in $0.5 \%$ CMC (1 and 5 $\mathrm{mg} / \mathrm{kg} /$ day, orally in $3^{\text {rd }}$ and $4^{\text {th }}$ groups respectively) for seven successive days and the last doses of NBV were administered one hour before gastric ulcer induction by IND on the $7^{\text {th }}$ day of the study period after $24 \mathrm{~h}$ of fasting. Rats were received NBV and its vehicle orally via non-installed orogastric tube. The selected doses of NBV were based on its effectiveness and safety as a protective agent in previous experimental studies (Ma et al., 2012; Nade et al., 2013). All fasted rats were deprived of food and allowed free access to water except for the last hour before injection of IND or its vehicle (Khattab et al., 2001).

\section{Blood and tissue samples:}

Three hours after the induction of gastric ulcer, blood samples were collected via cardiac puncture under ether anesthesia. Blood samples were left to clot in clean dry tubes and centrifuged at $855 \mathrm{x} \mathrm{g}$ for $10 \mathrm{~min}$ at $4^{\circ} \mathrm{C}$ to obtain the serum. Serum samples were stored at $-20^{\circ} \mathrm{C}$ for further biochemical analysis of tumor necrosis factor-alpha $(\mathrm{TNF}-\alpha)$ and interleukin-1 beta (IL-1ß). Then, the rats were sacrificed and the stomachs of all groups were excised for macroscopic examination and gastric ulcer scoring.

Immediately after macroscopic examination, the glandular part of each stomach (including ulcerated and nonulcerated areas) was scraped off gently using a glass slide to obtain gastric mucosa for quantitative real-time polymerase chain reaction (qRT-PCR) and tissue homogenate preparation for biochemical study. Then, the remaining part was preserved in $10 \%$ formalin for histopathological and immunohistochemical examination.

\section{Assessment of gastric mucosal lesions:}

The stomachs were dissected out and the glandular portion, at a region located $2 \mathrm{~mm}$ below the limiting ridge (margo plicatus) that separates the forestomach from the glandular part, was cut along the greater curvature and the mucosal surfaces were washed with cold normal saline to remove blood contaminant, if any. Ulcers of the gastric 
mucosa appear as elongated bands of hemorrhagic lesions parallel to the long axis of the stomach. The mucosal layer of stomach was examined using magnifying lens and was checked macroscopically for mucosal necrotic lesions, red streaks and red erosions. Total lesions number was counted and the scoring of lesions were determined based on the following; $0=$ no ulcer; $1=$ lesion size of $<1 \mathrm{~mm} ; 2=$ lesion of size 1 to $2 \mathrm{~mm} ; 3=$ lesion of size 2 to $3 \mathrm{~mm}$; $4=$ lesion of size $3-4 \mathrm{~mm}$ and $5=$ lesion of size $>4 \mathrm{~mm}$. The length of each lesion along its greatest diameter was measured and the sum of lengths was expressed as ulcer index (mm) (Valcavi et al., 1982) and the preventive index percentage (PI $\%$ ) was calculated according to the method of Hano et al. (1976) using the following formula.:

Preventive index \% (PI \%) = Ulcer index of ulcer group - Ulcer index of treated group/ Ulcer index of ulcer group x 100 .

Tissues homogenate preparation:

Gastric mucosa of stomach samples of all rats were homogenized in ice-cold saline using the maximum speed for one minute. The homogenate was centrifuged at $2376 \mathrm{x} \mathrm{g}$ for $5 \mathrm{~min}$ at $4^{\circ} \mathrm{C}$ and the resulting supernatants were kept in aliquots and stored at $-80^{\circ} \mathrm{C}$ till the determination of gastric mucosal parameters.

\section{Biochemical analysis of gastric} mucosa:

Determination of oxidative stress markers:

Oxidative stress markers were detected in the resultant supernatant of gastric mucosal homogenate. The appropriate kits (Biodiagnostic kits, Biodiagnostic Dokki, Giza, Egypt) were used for the determination of malondialdehyde (MDA), the end product of lipid peroxidation (Ohkawa et al., 1979). Activity of catalase (CAT) and superoxide dismutase (SOD) were assayed using the methods of Sinha, (1972) and Nishikimi et al. (1972) respectively. Reduced glutathione (GSH) level and glutathione peroxidase (GPx) activity were estimated based on the method of Ellman (1959) and Habig et al. (1974) respectively.

Determination of prostaglandin $\mathbf{E}_{2}$ ( $\mathrm{PGE}_{2}$ ) and nitric oxide (NO):

$\mathrm{PGE}_{2}$ content in supernatant was determined by competitive enzymelinked immunosorbent assay (ELISA) using a $\mathrm{PGE}_{2}$ kit provided by $\mathrm{R} \& \mathrm{D}$ Systems Inc., Minneapolis, Minnesota, USA. It was assessed according to the method of Hamberg \& Samuelsson, (1973).

Nitric oxide (NO) measurement is difficult because of its brief half-life. Therefore, nitrate/nitrite levels, which are stable degradation products of nitric oxide metabolism, were used as markers. It was quantified in gastric mucosal homogenate using commercial kits (Biodiagnostic, Dokki, Giza, Egypt) according to the method described by Miranda et al., (2001).

Determination of serum proinflammatory cytokines:

Tumor necrosis factor-alpha (TNF$\alpha)$ and interleukin-1beta (IL-1ß) were determined according to Corti et al. (1992) and Dinarello (1992) using a commercially available rat ELISA Kits (R\&D Systems Inc., Minneapolis, Minnesota, USA) following the instructions of the manufacturer.

\section{Histopathological examination:}

Gastric tissue samples were fixed in $10 \%$ formalin and tissue blocks prepared in paraffin. A strip of gastric wall was cut through the entire glandular mucosa, necessarily including red streaks or sites of ulceration. Sections were then 
deparaffinized and stained with haematoxylin and eosin (H\&E) for histological examination using light microscopy.

\section{Immunohistochemical analysis of} iNOS:

Immunohistochemical staining is a valuable tool for detecting specific antigens in tissues. In brief, five $\mu \mathrm{m}$ thick sections were prepared from different animal groups and immunohistochemistry was performed. Sections were deparaffinised, rehydrated, and endogenous peroxidase activity was blocked with $\mathrm{H}_{2} \mathrm{O}_{2}$ in methanol. Sections were pre-treated in citrate buffer ( $\mathrm{pH}$ 6.0) in microwave. Sections were incubated at room temperature with anti-inducible nitric oxide synthase (iNOS, Thermo Fisher Scientific, Wilmington, DE, USA). Sections were incubated with biotinylated goat anti-polyvalent, then with streptavidin peroxidase and finally with 3-3'-diamino-benzidine-tetrahydrochloride (DAB) plus chromogen. The negative control included sections incubated in the absence of the primary antibody. Slides were counterstained with hematoxylin and visualized using a Leica Quin 500 image analyzer computer system (Leica Image Systems Ltd, Cambridge, UK). Positivity for iNOS expression was seen as a distinct cytoplasmic brown stain under a light microscope.

Immunohistochemical evaluation and scoring of stained cells

Using the method of Detre et al. (1995), the histoscore (H-Score) semiquanitative method was used to score the degree of iNOS positive immunoreactivity of the gastric tissues. This method consists of the percentages of positively stained cells multiplied by the intensity of staining where the percentage of stained cells in each intensity category varying from (0$100 \%$ ) and the staining intensity of proteins within the cytoplasmic compartment for iNOS were scored from 0 to 3 (i.e. scores of $0,1,2$ or 3 corresponding to the no expression, mild, moderate and intense brown staining, respectively). Ten different areas were evaluated under a microscope for each slide (X 400 magnification). The average score per group were used for analysis of iNOS. The final score is ranging from 0 to 300 .

Extraction of RNA and quantitative real time- PCR (qRTPCR):

Total RNA extraction from the frozen gastric mucosal tissues was done by using total RNA Purification Kit (Jena Bioscience $\mathrm{GmbH}$ ) according to the manufacturer's instructions, about 25 mg stomach tissue put in a microcentrifuge tube with $300 \mu \mathrm{L}$ of lysis buffer containing 2ME (2 Mercapto Ethanol) was homogenized using rotor Tissue Ruptor (Qiagen, $\mathrm{GmbH}$ ). The purity and concentration of the RNA extracted was measured in nanometers (nm) using Nanodrop spectrophotometer (Thermo Fisher Scientific Inc., USA). The absorbance of Nanodrop spectrophotometer was measured at A260 and A280 nm. The ratio of the reading at (A260/A280) provides an estimate of the purity of RNA. Pure RNA has an A260/A280 ratio of 1.9 to 1.3. Template RNA $(5 \mu 1)$ and distilled water $(15 \mu \mathrm{l})$ were added to Maxine RT premix tube. cDNA synthesis (Reverse transcription) reaction using G-storm thermacycler (Ingland) was performed at a temperature of $45^{\circ} \mathrm{C}$ for 60 minutes followed by RTase inactivation step at $95^{\circ} \mathrm{C}$ for 5 minutes. This reactant was diluted by adding $30 \mathrm{ml}$ nuclease free 
water. RT-PCR was done using ABI 7900HT fast real time PCR (applied Biosystem USA), the prepared reaction components were done in 96 well PCR plate (micro Amp R 90 well optical reaction plate with Barcode, code 128). The reaction was done using qPCR Green Master from (Jena Bioscience $\mathrm{GmbH})$, using real time cycler conditions of $95^{\circ} \mathrm{C}$ and $5 \mathrm{~min}$ (Initial denaturation), followed by 35 cycles of $95^{\circ} \mathrm{C}, 30 \mathrm{~s}, 52^{\circ} \mathrm{C}$, one minute and $72^{\circ} \mathrm{C}$, 30 seconds for denaturation, annealing and extension steps, respectively. B-actin served as an internal control. The sequences of primers used in qRT-PCR are depicted in table (1). All data are expressed as fold-change in expression, compared to the expression in other animal groups, using the $2 \Delta \Delta C_{T}$ method (Livak and Schmittgen, 2001) in which $\mathrm{C}_{\mathrm{T}}$ indicates cycle threshold, the fractional cycle number where the fluorescent signal reaches detection threshold. The normalized $\Delta \mathrm{C}_{\mathrm{T}}$ value of each sample is calculated using up to an endogenous control gene, glyceraldehyde 3-phosphate dehydrogenase (GAPDH). Fold change values are presented as average fold change $=2^{-}$(average $\Delta \Delta \mathrm{C}_{\mathrm{T}}$ ) for genes in treated relative to control samples using RQ (relative quantity) manager program, 1.2 ABI SDS software (ABI 7900 HT).

Table (1): A list of primer sequences used for RT- PCR

\begin{tabular}{|l|r|r|}
\hline & Gene name & Sequence (5'- 3') \\
\hline \multirow{2}{*}{ iNOS } & Sense & 5'-ACCTTCCGGGCAGCCTGTGA-3' \\
\cline { 2 - 3 } & Antisense & 5'-CAAGGAGGGTGGTGCGGCTG-3' \\
\hline $\begin{array}{l}\text { GAPDH } \\
\text { (Control } \\
\text { gene })\end{array}$ & Sense & 5'-TGCTGGTGCTGAGTATGTCG-3' \\
\cline { 2 - 3 } & Antisense & 5'-TTGAGAGCAATGCCAGCC-3' \\
\hline
\end{tabular}

iNOS: inducible nitric oxide synthase, GAPDH: glyceraldehyde 3-phosphate dehydrogenase

\section{Statistical analysis:}

All data are expressed as mean \pm standard error (S.E.). Statistical evaluation was performed by one way analysis of variance (ANOVA) followed by Duncan's multiple range tests. All analyses were done using the computer program SPSS (version 17). $\mathrm{P}<0.05$ was selected as the level of statistical significance.

\section{RESULTS}

Ulcer number, scoring and index:

To explore the severity of gastric injury, the gastric mucosal lesions were assessed macroscopically. Ulcers of the gastric mucosa appear as elongated bands of hemorrhagic lesions parallel to the long axis of the stomach. Administration of IND (30 mg/kg, i.p.) induced severe gastric mucosal damage. Data given in Table (2) reveal that pretreated rats with NBV (1 and 5 $\mathrm{mg} / \mathrm{kg}$, p.o. for seven days in $3^{\text {rd }}$ and $4^{\text {th }}$ groups i.e. IND+NBV-1, and IND+NBV-5 respectively) resulted in a significant decrease in ulcer number and scoring compared to IND-treated rats of the second group. Also, there was a significant difference between IND+ NBV5 ( $4^{\text {th }}$ group) and IND + NBV1 $\left(3^{\text {rd }}\right.$ group). Moreover, administration of IND induced a remarkably high ulcer index. Pretreatment of rats with NBV (1 and 5 $\mathrm{mg} / \mathrm{kg}$, p.o. for seven days) significantly reduced the ulcer index induced by IND. 
Additionally, it was noticed that preventive index (PI) \% of NBV in a dose of $5 \mathrm{mg} / \mathrm{kg}(61.34 \%)$ was higher

than that of NBV in a dose of $1 \mathrm{mg} / \mathrm{kg}$ $(55.25 \%)$.

Table (2):Effect of pretreatment with nebivolol (NBV) on ulcer number, score, index and preventive index percentage in indomethacin-induced gastric ulcer (IND group).

\begin{tabular}{|l|l|l|l|l|}
\hline Groups & Ulcer number & Ulcer scoring & Ulcer index $(\mathrm{mm})$ & PI \% \\
\hline Control & n.d. & n.d. & n.d. & - \\
\hline IND & $11.25 \pm 0.53^{\mathrm{a}}$ & $4.43 \pm 0.04^{\mathrm{a}}$ & $23.13 \pm 1.30^{\mathrm{a}}$ & - \\
\hline $\begin{array}{l}\text { IND+NBV- } \\
1\end{array}$ & $6.12 \pm 0.32^{\mathrm{b}}$ & $3.40 \pm 0.07^{\mathrm{b}}$ & $10.35 \pm 0.40^{\mathrm{b}}$ & 55.25 \\
\hline $\begin{array}{l}\text { IND+NBV- } \\
5\end{array}$ & $5.12 \pm 0.24^{\mathrm{c}}$ & $3.10 \pm 0.10^{\mathrm{c}}$ & $8.94 \pm 0.49^{\mathrm{c}}$ & 61.34 \\
\hline
\end{tabular}

Data are presented as mean \pm S.E., $n=8$, n.d.: not detectable, PI \% : Preventive index percentage.

Within the same column, different letters indicate statistical significance $(P<0.05)$ by Duncan's multiple range test.

Biochemical results:

Determination of oxidative stress markers:

IND-treated rats showed significant changes on oxidative stress markers with a significant increase in gastric mucosal MDA level compared to control rats. Pretreatment of IND-treated rats with both doses of NBV (1 and $5 \mathrm{mg} / \mathrm{kg}$ ) significantly reduced the MDA level compared to IND group. There was a significant difference between pretreated groups (Table 3). Significant decrease in levels of SOD and CAT enzymes were observed after IND administration when compared with control rats. Both groups of pretreatment with NBV (1 and 5 $\mathrm{mg} / \mathrm{kg}$, p.o) showed significant increase in levels of gastric mucosal SOD and
CAT as compared to rats treated with IND (Table 3).

Regarding GPx, its activity in rats administered IND was significantly decreased compared to control group. The decrease in GPx activity of INDtreated rats significantly increased by pretreatment with both doses of NBV (1 and $5 \mathrm{mg} / \mathrm{kg}$, p.o.) (Table 3).

The gastric mucosal homogenate content of reduced GSH was depleted significantly in IND-treated group as compared to control group. However, pretreatment with NBV (1 and $5 \mathrm{mg} / \mathrm{kg}$, p.o.) significantly elevated the GSH content when compared to IND-treated group. The results showed significant differences between both doses of NBV in SOD, CAT, GPx activities, reduced GSH content and MDA level (Table 3). 
Table (3):Effect of pretreatment with nebivolol (NBV) on gastric mucosal malondialdehyde (MDA), superoxide dismutase (SOD), catalase (CAT), glutathione peroxidase (GPx), and reduced glutathione (GSH) in indomethacininduced gastric ulcer (IND group).

\begin{tabular}{|l|l|l|l|l|l|}
\hline Groups & $\begin{array}{l}\text { MDA } \\
(\mathbf{n m o l} / \mathbf{g})\end{array}$ & $\begin{array}{l}\text { SOD } \\
(\mathbf{U} / G)\end{array}$ & $\begin{array}{l}\text { CAT } \\
(\mathbf{U} / G)\end{array}$ & $\begin{array}{l}\text { GPx } \\
(\mathbf{U} / G)\end{array}$ & $\begin{array}{l}\text { GSH } \\
(\mathbf{m m o l} / \mathbf{g})\end{array}$ \\
\hline Control & $20.83 \pm 1.6^{\mathrm{a}}$ & $67.9 \pm 2.1^{\mathrm{a}}$ & $80.36 \pm 4.2^{\mathrm{a}}$ & $125.2 \pm 5.4^{\mathrm{a}}$ & $53.1 \pm 1.7^{\mathrm{a}}$ \\
\hline IND & $58.42 \pm 4.1^{\mathrm{b}}$ & $39.6 \pm 1.4^{\mathrm{b}}$ & $39.58 \pm 3.7^{\mathrm{b}}$ & $69.7 \pm 3.2^{\mathrm{b}}$ & $38.2 \pm 1.4^{\mathrm{b}}$ \\
\hline IND+NBV-1 & $45.21 \pm 1.5^{\mathrm{c}}$ & $44.8 \pm 1.6^{\mathrm{c}}$ & $52.22 \pm 4.4^{\mathrm{c}}$ & $97.3 \pm 3.4^{\mathrm{c}}$ & $42.6 \pm 1.2^{\mathrm{c}}$ \\
\hline IND+NBV-5 & $38.68 \pm 2.1^{\mathrm{d}}$ & $50.3 \pm 1.8^{\mathrm{d}}$ & $66.59 \pm 4.6^{\mathrm{d}}$ & $109.6 \pm 4.1^{\mathrm{d}}$ & $46.5 \pm 1.2^{\mathrm{d}}$ \\
\hline
\end{tabular}

Data are presented as mean \pm S.E., $n=8$.

Within the same column, different letters indicate statistical significance $(P<0.05)$ by Duncan's multiple range test.

Determination of prostaglandin $\mathbf{E}_{2}$ (PGE $)_{2}$ and nitric oxide (NO):

Compared with findings in the control group, the level of gastric mucosal $\mathrm{PGE}_{2}$ was significantly decreased in IND group. Pretreatment of IND treated rats with both doses of NBV (1 and $5 \mathrm{mg} / \mathrm{kg}$, p.o.) resulted in significant increase in $\mathrm{PGE}_{2}$ level when compared to IND group (Table 3). Administration of IND resulted in a significant increase in gastric mucosal nitrite/nitrate (NO) content comparing to the control group. NBV pretreatment (1 and $5 \mathrm{mg} / \mathrm{kg}$, p.o.) led to a significant decrease in gastric mucosal NO compared to IND group (Table 4).

Determination of serum proinflammatory cytokines:

Table 4: Effect of pretreatment with Nebivolol (NBV) on gastric mucosal prostaglandin $\mathrm{E}_{2}\left(\mathrm{PGE}_{2}\right)$ and nitite/nitrate levels and on serum tumor necrosis factoralpha (TNF- $\alpha$ ) and interleukin- $\beta 1$ (IL- $\beta 1)$ in indomethacin-induced gastric ulcer (IND group).

\begin{tabular}{|l|l|l|l|l|}
\hline Groups & $\begin{array}{l}\mathrm{PGE}_{2} \\
(\mathrm{ng} / \mathrm{g} \text { wet tissue })\end{array}$ & $\begin{array}{l}\text { Nitrite/nitrate } \\
(\text { nmol/g wet tissue })\end{array}$ & $\begin{array}{l}\text { TNF- } \alpha \\
(\mathrm{pg} / \mathrm{ml})\end{array}$ & $\begin{array}{l}\text { IL-ß1 } \\
(\mathrm{pg} / \mathrm{ml})\end{array}$ \\
\hline Control & $295.6 \pm 18.4^{\mathrm{a}}$ & $209.6 \pm 11.7^{\mathrm{a}}$ & $314.8 \pm 12.2^{\mathrm{a}}$ & $51.28 \pm 1.9^{\mathrm{a}}$ \\
\hline IND & $83.6 \pm 9.2^{\mathrm{b}}$ & $295.5 \pm 14.2^{\mathrm{b}}$ & $438.5 \pm 14.7^{\mathrm{b}}$ & $97.40 \pm 2.4^{\mathrm{b}}$ \\
\hline IND+NBV-1 & $108.7 \pm 5.3^{\mathrm{c}}$ & $244.2 \pm 10.4^{\mathrm{c}}$ & $396.2 \pm 10.4^{\mathrm{c}}$ & $88.25 \pm 2.5^{\mathrm{c}}$ \\
\hline IND+NBV-5 & $137.5 \pm 7.8^{\mathrm{d}}$ & $253.8 \pm 11.5^{\mathrm{c}}$ & $360.7 \pm 11.9^{\mathrm{d}}$ & $79.33 \pm 2.1^{\mathrm{d}}$ \\
\hline
\end{tabular}

Data are presented as mean \pm S.E., $n=8$.

Within the same column, different letters indicate statistical significance $(P<0.05)$ by

Duncan's multiple range test 


\section{Histopathological results}

The histological appearance of the stomach tissue of the rats from control group revealed features of intact mucosa with regular glands and normal submucosa with no observable microscopic pathological lesion (fig. 1A). On the other hand, the stomach tissue sections of IND- treated rats showed extensive gastric mucosal erosions in the glandular part of the stomach, sloughing of gastric glands and exfoliated cells appearing in the lumen, exposed muscularis mucosa, submucosal edema and congestion of blood vessels. (Fig.1- B). In the areas with no erosion, vacuolated cytoplasm and pyknotic nuclei of the gastric mucosal epithelium was detected denoting necrotic changes. In addition, inflammatory leukocytic infiltration with vascular congestion was observed in the field (fig. 1- C). The microscopic examination of stomach from IND-administered rats pretreated with NBV (1 mg/kg) showed that gastric epithelium was protected to some extent, congested blood vessels and leukocytic infiltration was observed (fig. 1- D). Pretreatment with NBV $(5 \mathrm{mg} / \mathrm{kg})$ attenuated, but didn't completely prevent the histopathological changes- induced by IND and inflammatory infiltration was still evident (fig. 1- E).

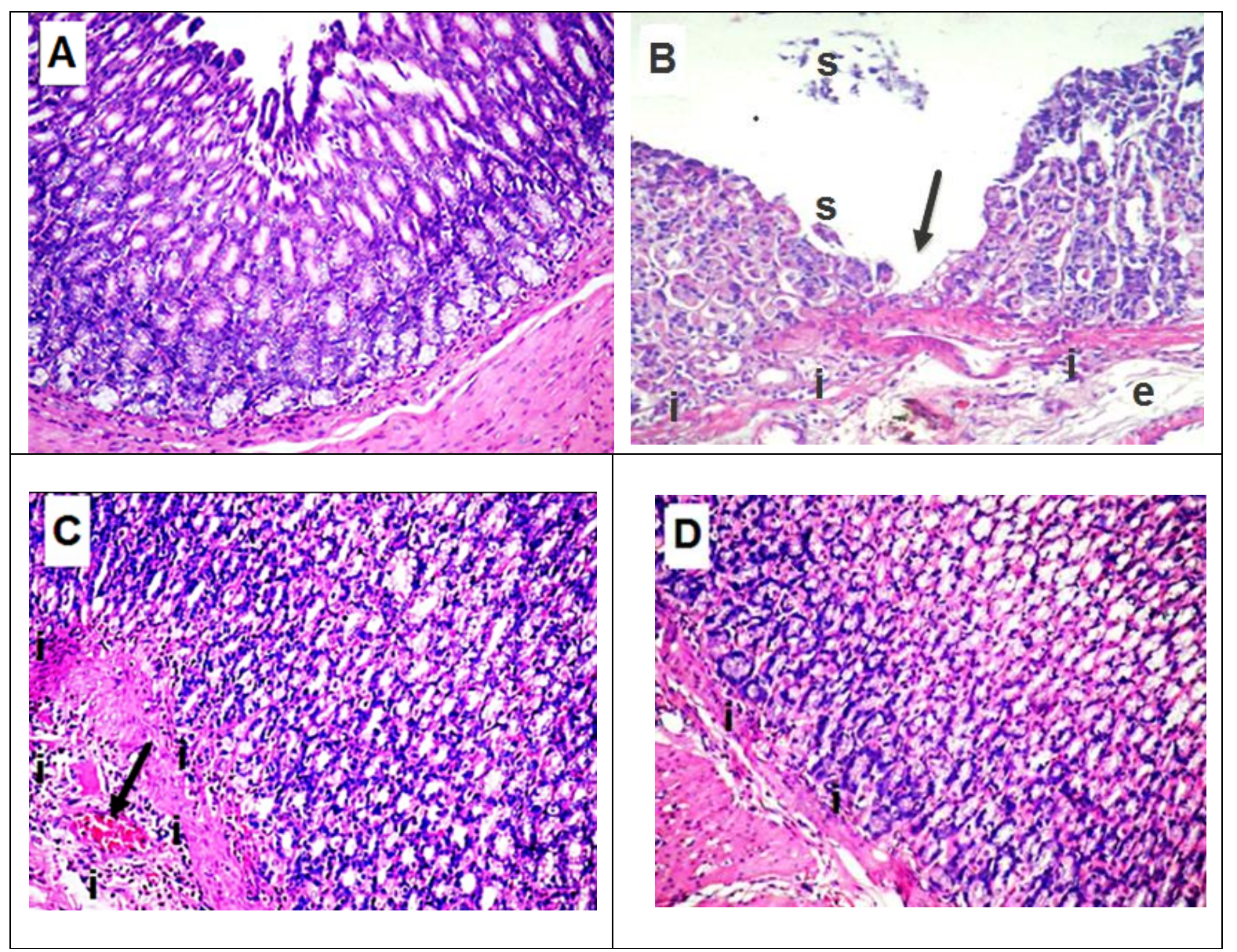

Figure (1): Effect of pretreatment with nebivolol on gastric mucosal sections in indomethacin-treated rats (H\&E, magnification X200) (A) Control group showing normal mucosal architecture, intact epithelial surface with normal submucosal and muscularis layers; (B) IND-treated rats elicited erosion of the surface mucous cells (arrows), massive sloughing of the superficial parts of gastric glands (s) with 
exposed muscularies mucosa. Submucosal edema (e) and inflammatory cellular infiltration (i) were noticed; (C) IND+ NBV1-treated rats showed restoration of gastric mucosal cells. Inflammatory infiltration (i) and congested blood vessel (arrow) were detected; (D) IND+ NBV 5- treated rats showed preservation of gastric mucosal architecture and an outline similar to that of control rats except presence of mild inflammatory infiltration (i).

Immunohistochemical results:

Expressions and scores related to immunohistochemical analysis of iNOS were summarized in figure (2). Immunohistochemical detection of iNOS was used as a marker of NO formation in the gastric tissue. Examinations of rat gastric mucosa revealed that IND administration significantly increased the expression of iNOS in the cytoplasm of gastric glandular cells. However, pretreatment with NBV (1 and $5 \mathrm{mg} / \mathrm{kg}$, p.o. for seven days) significantly attenuated iNOS expression when compared to IND- treated rats.
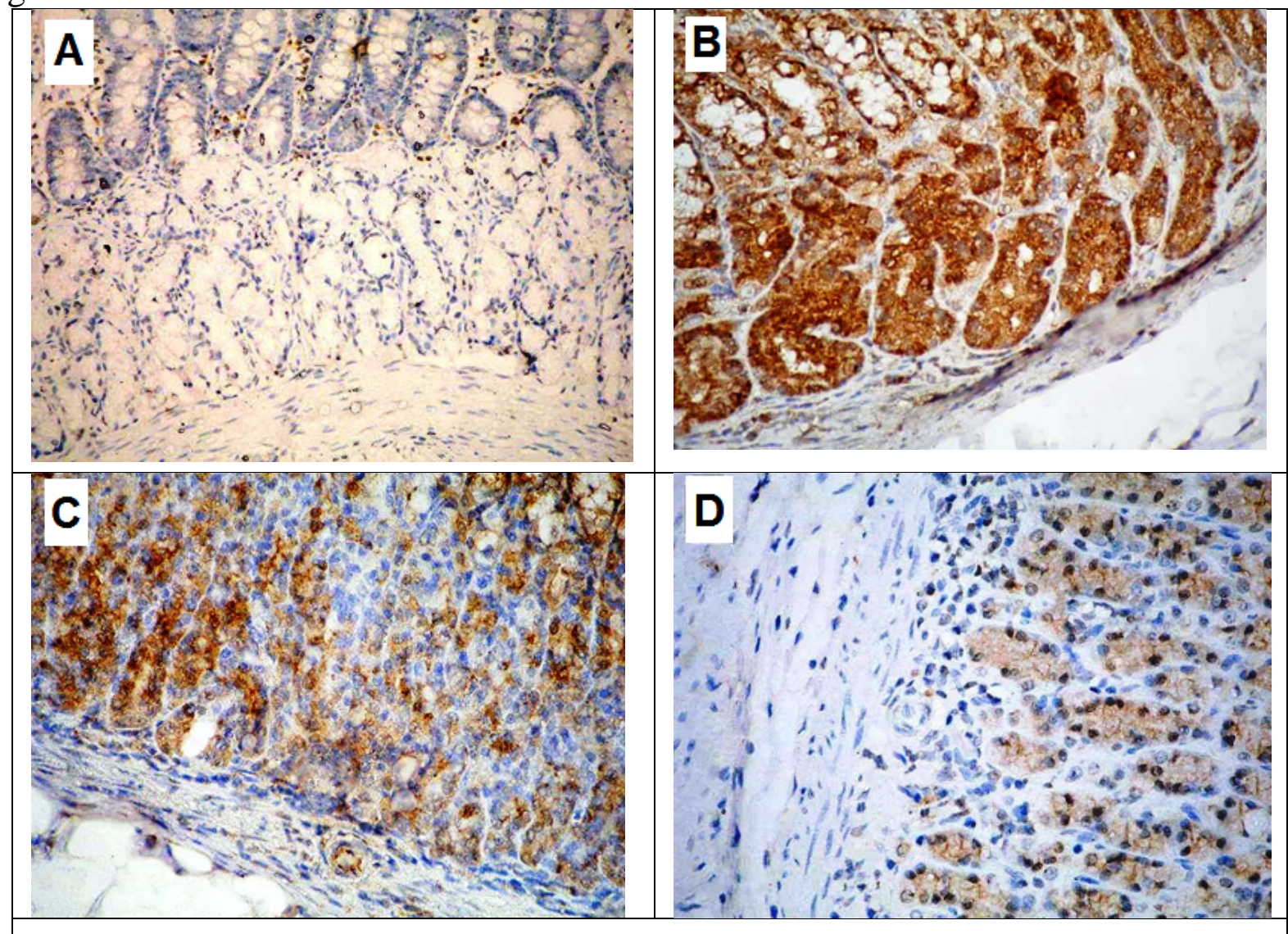


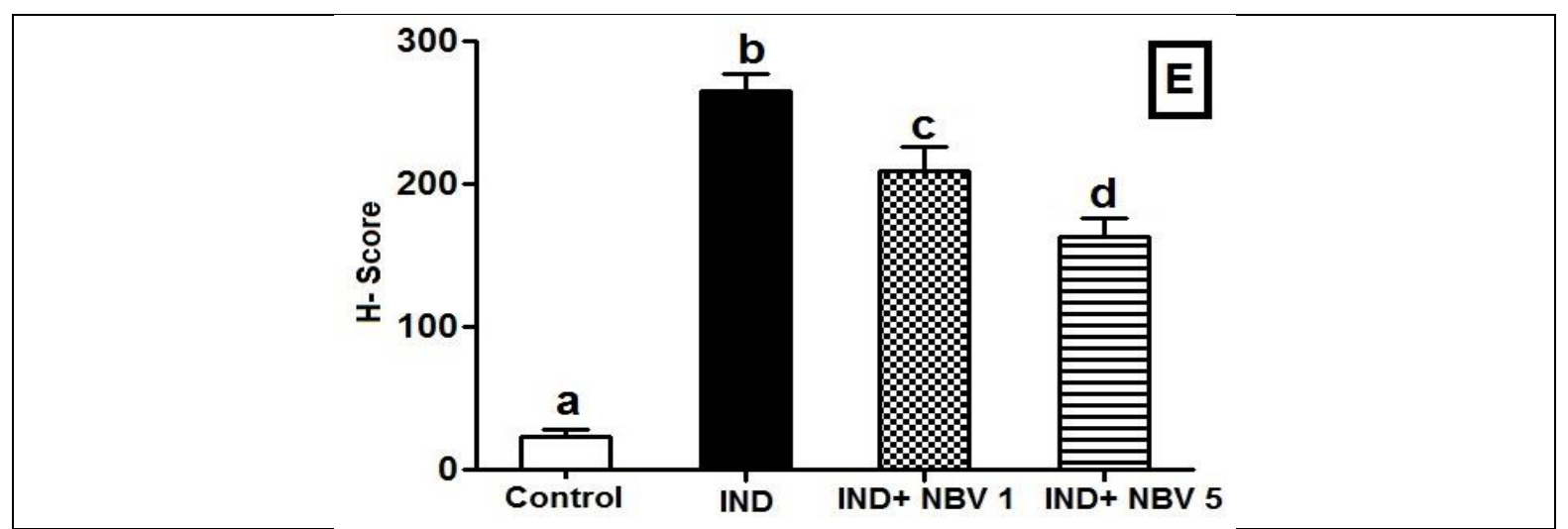

Figure (2): Effect of pretreatment with nebivolol on immunohistochemical staining of inducible nitric oxide synthase (iNOS) in the gastric mucosa of indomethacintreated rats (magnification x 400).

(A) Control group showing minimal expression of iNOS in the extent and intensity in the gastric mucosal cells; (B) IND group showing extensive expression in iNOS immunoreactivity in the cytoplasm of gastric epithelial cells; (C, D) IND+NBV-1, and IND+NBV-5 groups demonstrating a significant reduction in iNOS immunostaining.

Brown color indicates iNOS positivity; (E) Quantification of iNOS represents Hscore.

Data are presented as mean \pm S.E., $\mathrm{n}=8$. Different letters above the columns indicate statistical significance $\mathrm{P}<0.05$ by Duncan's multiple range test.

Effect of NBV on mRNA significantly decreased the level of expression of iNOS gene:

As shown in figure 3, the expression of iNOS mRNA in the gastric mucosa was significantly increased in IND treated group compared to control rats. Pretreatment with NBV (1 and 5 $\mathrm{mg} / \mathrm{kg}$, p.o. for seven days prior to IND )

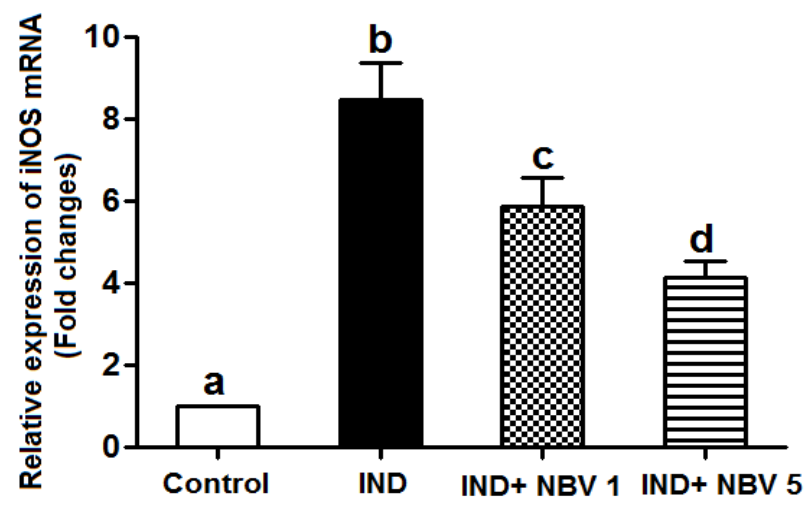

Figure (3): Effect of pretreatment with nebivolol on mRNA expression of inducible nitric oxide synthase (iNOS) in indomethacin-treated rats (IND, $30 \mathrm{mg} / \mathrm{kg}$, i.p.). Data are presented as mean \pm S.E., $\mathrm{n}=8$.

Different letters above the columns indicate statistical significance $\mathbf{P}<0.05$ by Duncan's multiple range test. 


\section{DISCUSSION}

The present study investigated the gastroprotective effect of nebivolol and further extents the findings of Morsy et al. (2012), showing additive gastroprotective mechanisms of nebivolol, including the role of mucosal $\mathrm{PGE}_{2}$ and iNOS expression, in an indomethacin-induced gastric ulcer model.

The results of the current study revealed that indomethacin administration significantly caused ulceration in the glandular area of the rat stomach as observed in the histopathological examination, associated with significant elevations in ulcer number and index. These results are in agreement with previous reports demonstrating that indomethacin causes ulcerative lesions in the gastric mucosa in rats (Kim et al., 2011; Thong-Ngam et al., 2012). Nebivolol protected rats from indomethacin-induced gastric ulceration as evidenced by significantly reduced ulcer number and index. These results are further supported by the histopathological findings which showed that pretreatment with nebivolol ameliorated congestion, hemorrhage, edema, inflammatory changes and erosions caused by indomethacin in the gastric tissue.

Nitric oxide (NO) is a mediator not only of gastrointestinal mucosal defense but also of its damage (Calatayud et al., 2001). In the stomach, NO, produced by constitutive enzyme isoform (cNOS), is cytoprotective and NO produced by the inducible enzyme (iNOS) is cytotoxic. In general, the endothelial and mucosal NOS isoforms produce low amounts of NO. However, the high quantity of NO produced by iNOS can damage the epithelium (Wallace \& Miller, 2000). On the other hand, low concentration of
NO derived from cNOS is implicated in mechanisms maintaining the integrity of the gastric epithelium. Moreover, it regulates gastric blood flow and directly stimulates gastric mucus secretion by activating soluble guanylate cyclase (Cho, 2001). Furthermore, this protective effect of $\mathrm{NO}$ is due to the inhibition of activation, adhesion and migration of leukocytes in the inflammatory area (Lanas, 2008).

In the current study, indomethacin induced a significant increase in the gastric mucosal nitrite/nitrate levels. Such increase caused by indomethacin, which was reported by Fouad et al. (2010), may be attributed to the observed increase in iNOS expression in the ulcerated gastric mucosa. In consistence with our results, Konturek et al. (2000) concluded that the increased production of NO due to the overexpression of iNOS is one of the mechanisms by which NSAIDs damages the gastric mucosa. Moreover, Motawi et al. (2008) reported that indomethacin decreases tissue cNOS-derived NO and increases iNOS-derived NO.

In this study, nebivolol induced significant decrease in iNOS expression and mucosal nitrite/nitrate levels compared to indomethacin administered rats, this may be attributed in part to the increased consumption of NO in free radical scavenging, hindering lipid peroxidation and to the stimulation of cNOS in gastric tissue which produce a low concentration of cytoprotective NO. These data depict the involvement of NO pathway in anti-ulcerogenic potential of nebivolol. Several reports have demonstrated the NO-mediated beneficial effects of nebivolol on different tissues. Nebivolol has been shown to produce NO-mediated relaxation of the rat mesenteric vascular 
bed and increase cNOS activity in cultured bovine coronary postcapillary endothelial cells (Parenti et al., 2000). Nebivolol has also been found to induce relaxation of rat renal glomerular vasculature by increasing NO release (Kalinowski et al., 2003) ' Another study by Zhou et al., (2010) demonstrated that the vasodilatory and anti-oxidant properties of nebivolol are likely through reduction in NADPH oxidase activity and enhancement of endothelial NO synthase activity. Besides, it has been reported that nebivolol treatment leads to reductions in NADPH oxidase activity in the heart and vascular tissue (Sorrentino et al., 2011). A study by Manrique et al., (2011) has highlighted that nebivolol induced improvement in insulin metabolic signaling and enhancement in bioavailable NO in skeletal muscle.

Other than the important role of NO in maintenance of blood flow, it may protect against indomethacin-induced gastric damage by promotion of prostaglandins (PGs) synthesis. PGs, especially $\mathrm{PGE}_{2}$, modulate a number of components of mucosal defense as they stimulate mucus and bicarbonate secretion, increase mucosal blood flow, increase the resistance of epithelial cells to cytotoxins-induced injury and suppress the recruitment of leukocytes into gastric mucosa. PGs can also down regulate the release of other inflammatory mediators that may contribute to the generation of gastric ulcer. $\mathrm{PGE}_{2}$ has been shown to be a potent inhibitor of TNF- $\alpha$ and IL-1 release from macrophages and of leukotriene B4 and IL-8 release from neutrophils (Martin \& Wallace, 2006).

A well-known mechanism responsible for gastric damage induced by indomethacin is the inhibition of COX, a rate-limiting enzyme in the synthesis of PGs (Suleyman et al., 2009). In accordance with our results, Koizumi et al., (2009) reported that indomethacin resulted in a significant reduction in $\mathrm{PGE}_{2}$ levels in rats. $\mathrm{A}$ mutual interaction was shown to exist between NOS and COX enzymes. Drugs which increase NO were shown to enhance COX activity whereas NOS inhibitors blocked $\mathrm{PGE}_{2}$ production (Salvemini et al., 1993). Consequently, pretreatment of rats with nebivolol in the present study ameliorated the deleterious effects of indomethacin on gastric tissues through elevation of gastric mucosal $\mathrm{PGE}_{2}$ level. To the best of our knowledge, the current study is the first to report that nebivolol administration causes increase in gastric mucosal $\mathrm{PGE}_{2}$. However in support, Kaan et al. (1996) reported that propranolol, a $\beta$ adrenoceptor blocker, increases the $\mathrm{PGE}_{2}$ levels in gastric mucosa which may explain its anti-ulcer effects. Further possible modes of gastroprotective action of nebivolol may be due to its possible antioxidant effects. The role of oxidative stress and inflammation in the pathogenesis of indomethacin-induced gastric damage is well established (Yadav et al., 2012). Several studies have suggested that indomethacin has pro-oxidant activity and initiate lipid peroxidation by generating reactive oxygen species (ROS), thereby interfering with endogenous antioxidant systems of the mucosa cells. Sinha et al. (2015) reported that, indomethacin significantly augmented ROS production in the gastric tissue and simultaneously reduced the activity and/or level of the antioxidant enzymes SOD, GST and CAT. In addition, SOD and GPx levels were found to be significantly reduced in gastric tissues of rats treated with 
indomethacin (Carrasco-Pozo et al. 2011). Consistent with these findings, the present work revealed that administration of IND significantly increased the lipid peroxidation (MDA) and decreased the level of nonenzymatic (GSH) and the activity of enzymatic (SOD, CAT, GPx) antioxidants in the gastric mucosal tissue of IND-administered rats. Therefore, our results suggested that the inhibition of these enzymatic activities and decrease GSH are, at least in part, responsible for oxidative tissue damage of gastric mucosa occurring after IND treatment. The antioxidant properties of nebivolol observed in this study, as it decreased MDA level and increased non-enzymatic and enzymatic antioxidants, are supported by the findings of various previous studies. For example, nebivolol has been reported to reduce MDA level in a rat model of metabolic syndrome due to its antioxidant activity (Toblli et al. 2010).

In this study, nebivolol - induced a significant increase in GSH (an important non-enzymatic antioxidant) which is in accord with the findings of Goel et al. (2009) who reported that chronic administration of nebivolol shows significant increase in brain GSH level. Moreover, Rizzi et al. (2014) found evidence that nebivolol as a selective $\beta 1$-blocker with antioxidant properties attenuates hypertensioninduced left ventricular hypertrophy and cardiac collagen deposition in association with significant cardiac antioxidant effects in rats. In line with those findings, nebivolol attenuated the vascular remodeling associated with increased oxidative stress in hypertensive rats (Ceron et al., 2013). Dursun et al. (2014) reported that nebivolol showed an antioxidant effect besides its low density lipoprotein lowering effect in a rat model of N-nitroL-arginine methyl ester (L-NAME)induced oxidative stress, vascular inflammation, and arteriosclerosis. In an experimental study, nebivolol was shown to prevent oxidative stress in rats with ischemia-induced cerebral injury (Uzar et al. 2012). Accordingly, nebivolol may reduce oxidative stress in skeletal muscle tissue by reducing both $\mathrm{NADPH}$ oxidase and mitochondrial generation of ROS (Whaley-Connell et al. 2009).

Besides oxidative stress, inflammation also plays a major role in the pathogenesis of NSAIDs induced gastropathy (Musumba et al., 2009). Oxidative stress is associated with proinflammatory cytokine production and, thus inflammation (Bindu et al., 2013). The inflammation induced in the gastric mucosa by indomethacin is accompanied by increased TNF- $\alpha$ production (Sinha \& Sil, 2015), which augments neutrophil-derived superoxide generation (Kwiecien et al., 2002) and stimulates IL-1 $\beta$ production, leading to neutrophil accumulation (Sinha \& Sil, 2015).

In the present study, indomethacin administration increased the serum levels of TNF- $\alpha$ and IL-1 $\beta$. In accordance with the current results, a previous study demonstrated that indomethacin-induced acute gastric ulceration resulted in increased production of TNF- $\alpha$ (Zhang et al., 2008). Apart from this, Yadav et al. (2012) pointed out that TNF- $\alpha$ upregulation was the primary event to initiate and induce gastric ulceration. They also suggest that mitigation of TNF- $\alpha$ may offer a potential solution to indomethacin-mediated gastropathy. In contrast, pretreatment of rats with 
nebivolol ameliorated the increases in TNF- $\alpha$ and IL-1 $\beta$ levels. The antiinflammatory effects of nebivolol were elicited by several previous findings; Garbin et al. (2008) showed that nebivolol significantly reduced oxidative stress-induced TNF- $\alpha$ and IL- 6 gene expression in human umbilical vein endothelial cells in an in vitro model. Wolf et al. (2008) also observed that nebivolol induces down-regulation of nuclear factor-kB (NF-kB)-dependent genes involved in inflammatory processes such as IL-1a, COX 2 and TNF- $\alpha$. In addition, Zapater et al. (2012) reported that nebivolol acted as a modulator of excessive hepatic proinflammatory response in the mice model of induced liver damage. In contrast, Górska et al. (2010) concluded that nebivolol did not modify lipopolysaccharides (LPS) - stimulated serum concentrations of TNF- $\alpha$, IL- $1 \beta$ and IL-6 in normotensive or hypertensive rats.

\section{CONCLUSION}

The present study supports and validates the promising gastroprotective efficacy of nebivolol against indomethacin-induced gastric ulceration and affords gastroprotective mechanisms via maintenance of mucosal $\mathrm{NO}$ and $\mathrm{PGE}_{2}$. In addition, the study confirmed the antioxidant and anti-inflammatory effects of nebivolol which are necessary to ameliorate the deleterious effects of indomethacin on gastric tissues. Thus, this study focuses the attention for the use of nebivolol in hypertensive patients suffering from NSAIDs-induced gastropathy. However, further investigations are needed to confirm the clinical applicability of this study.

\section{ACKNOWLEDGMENT}

The authors gratefully acknowledge Prof. Fouad El Debakey (Department of Biochemistry, Faculty of Medicine, Benha University, Egypt) for his assistance in biochemical analysis and PCR technique, and Dr. Ghada A. AbdElfattah (Department of Pathology, Faculty of Medicine, Benha University, Egypt) for her kind help in the histopathological and immunohistochemical part of this study.

\section{REFERENCES}

Bacic-Vrca, V.; Marusic, S.; Erdeljic V, et al. (2010): The incidence of potential drug-drug interactions in elderly patients with arterial hypertension. Pharmacy world and Science, 32: 815-821.

Bindu, S.; Mazumder, S.; Dey, S., et al. (2013): Nonsteroidal antiinflammatory drug induces proinflammatory damage in gastric mucosa through NF-kappaB activation and neutrophil infiltration: anti-inflammatory role of heme oxygenase-1 against nonsteroidal anti-inflammatory drug. Free Radical Biology and Medicine, 65:456-467.

Calatayud, S.; Barrachina, D. and Espluges, J.V. (2001): Nitric oxide: relation to integrity, injury, and healing of the gastric mucosa. Microscopy Research and Technique, 53:325- 335.

Carrasco-Pozo, C.; Speisky, H.; Brunser, O., et al. (2011): Apple peel polyphenols protect against gastrointestinal mucosa alterations induced by indomethacin in rats. Journal of Agricultural and Food Chemistry, 59 (12):6459-6466.

Ceron, C.S.; Rizzi, E.; Guimaraes, D.A., et al. (2013): Nebivolol 
attenuates prooxidant and profibrotic mechanisms involving TGF- $\beta$ and MMPs, and decreases vascular remodeling in renovascular hypertension. Free Radical Biology and Medicine, 65C:47-56.

Cho, C.H. (2001): Current roles of nitric oxide in gastrointestinal disorders. Journal of Physiology Paris, 95:253256.

Corti, A.; Fassino, J.; Marcucci, F., et al. (1992): Oligometric tumor necrosis factor- $\alpha$ slowly converts into the reactive forms at bioactive levels. The biochemical Journal, 284:905-910.

Detre, S.; Saciani, J.G. and Dowsett, M. (1995): A 'quickscore' method for immunohistochemical semiquantitation validation for oestrogen receptor in carcinomas. Journal of Clinical Pathology, 48: 876- 878.

Dinarello, C.A. (1992): ELISA kits based on monoclonal antibodies do not measure total IL-1 beta synthesis. Journal of Immunological Methods, 8: 148 (1-2):255- 259.

Dursun, S.; Çuhadar, S.; Köseoğlu, M., et al. (2014): The antiinflammatory and antioxidant effects of pravastatin and nebivolol in rat aorta. Anadolu Kardiyoloji Dergisi, 14: 229-233.

Ellman, G.L. (1959): Tissue sulfhydryl groups. Archives Biochemistry and Biophysics, 82:70-77.

Fongemie, J. and Felix- Getzik, E. (2015): A review of nebivolol pharmacology and clinical evidence. Drugs, 75: 1349- 1371.

Fouad, A.A.; Al-Sultan, A.I.; Yacoubi, M.T. and Gomaa, W. (2010): Ameliorative effects of telmisartan in diabetic rats with indomethacininduced gastric ulceration. European
Journal of Pharmacology, 637: 162170.

Garbin, U.; Fratta Pasini, A.; Stranieri, C., et al. (2008): Effects of nebivolol on endothelial gene expression during oxidative stress in human umbilical vein endothelial cells. Mediators of Inflammation, 2008: 367-590.

Goel, R.; Goel, A.; Manocha, A., et al. (2009): Influence of nebivolol on anticonvulsant effect of lamotrigine. Indian Journal of Pharmacology, 41:41-46.

Górska, D.; Dudarewicz, M.; Czarnecka, E. and Andrzejczak, D. (2010): Dose nebivolol influence serum concentrations of proinflammatory cytokines in hypertensive (SHR) and normotensive (WKY) rats? Pharmacological Reports, 62 (1): 8694.

Habig, W.H.; Pabst, M.J. and Jakoby, W.B. (1974): Glutathione-stransferases: The first enzymatic step in mercapturic acid formation. The Journal of Biological Chemistry, 249: 7130- 7139.

Hamberg, M. and Samuelsson, B. (1973): Detection and isolation of an endoperoxide intermediate in prostaglandin biosynthesis. Proceedings of the National Academy of Sciences of the United States of America, 70: 899- 903.

Hano, J. Bugajski, J.; Danek, L. and Wantuch, C. (1976): The effect of neuroleptics on the development of gastric ulcers in rats exposed to restraint-cold stress. Poland Journal of Pharmacology and Clinical Pharmacy, 28: 37-47.

Kaan, S.K.; Mei, Q.b. and Cho, C.H. (1996): A mechanistic study of betaadrenoceptor antagonists on ethanol- 
induced gastric damage. European Journal of pharmacology, 317:115122.

Kalafutova, S.; Juraskova, B. and Vlcek, J. (2014): The impact of combinations of non-steroidal antiInflammatory drugs and antiHypertensive agents on blood pressure. Advances in clinical and experimental medicine, 23 (6): 9931000.

Kalinowski, L.; Dobrucki, L.W.; Szczept-Konkel, M., et al. (2003): Third-generation beta- blockers stimulate nitric oxide release from endothelial cells through ATP efflux: A novel mechanism for antihypertensive action. Circulation, 107: 2747- 2752.

Khattab, M.M.; Gad, M.Z. and Abdallah, D. (2001): Protective role of nitric oxide in indomethacininduced gastric ulceration by a mechanism independent of gastric acid secretion. Pharmacological Research, 43: 463- 467.

Kim, J.H.; Kim, B.W.; Kwon, H.J. and Nam, S.W. (2011): Curative effect of selenium against indomethacin-induced gastric ulcers in rats. Journal of Microbiology and Biotechnology, 21(4): 400- 404.

Koizumi, S.; Odashima, M.; Otaka, M., et al. (2009): Attenuation of gastric mucosal inflammation induced by indomethacin through activation of the A2A adenosine receptor in rats. Journal of Gastroenterology, 44:419- 425.

Konturek, P.C.; Kania, J.; Hahn, H.G. and Konturek, J.W. (2000): Ascorbic acid attenuates aspirininduced gastric damage: role of inducible nitric oxide synthase. Journal of Physiology and Pharmacology, 119: 512-520.
Kwiecien, S.; Brzozowski, T. and Konturek, S.J. (2002): Effects of reactive oxygen species action on gastric mucosa in various models of mucosal injury. Journal of Physiology and Pharmacology, 53( 1): $39-50$.

Lanas, A. (2008): Role of nitric oxide in the gastrointestinal tract. Arthritis Research and Therapy,10:1-6.

Livak, K.J. and Schmittgen, T.D. (2001): Analysis of relative gene expression data using real- time quantitative PCR and the 2(T) (Delta C) method. Methods, 25 (4):402-408.

Ma, L.; Gul, R.; Habibi, J., et al. (2012): Nebivolol improves diastolic dysfunction and myocardial remodeling through reductions in oxidative stress in the transgenic (mRen2) rat. American journal of physiology. Heart and circulatory physiology, 302: H2341- H2351.

Maity, B.; Banerjee, D.; Bandyopadhyay, S.K. and Chattopadhyay, S. (2009): Regulation of arginase / nitric oxide synthesis axis via cytokine balance contributes to the healing action of malabaricone B against indomethacin-induced gastric ulceration in mice. International immunopharmacology, 9:491- 498.

Manrique, C.; Lastra, G.; Habibi, J., et al. (2011): Nebivolol improves insulin sensitivity in the TGR (Ren 2) 27 rat. Metabolism, 60: 17571766.

Martin, G.R. and Wallace, J.L. (2006): Gastrointestinal inflammation: a central component of mucosal defense and repair. Experimental Biology and Medicine (Maywood), 231:130-137. 
Miranda, K.M.; Espey, M.G. and Wink DA (2001): A rapid, simple spectrophotometric method for simultaneous detection of nitrate and nitrite. Nitric Oxide, 5: 62-71.

Morsy, M.A.; Heeba. G.H.; Abdelwahab, S.A. and Rofaeil, R.R. (2012): Protective effects of nebivolol against cold restraint stress-induced gastric ulcer in rats: Role of NO, HO-1, and COX-1,2. Nitric Oxide, 27: 117-122.

Motawi, T.K.; Abd Elgawad, H.M. and Shahin, N.N. (2008): Gastroprotective effect of leptin in indomethacin-induced gastric injury. Journal of Biomedical Science, 15:405-12.

Mourad, F.H.; Khuri, M.; Shouaib, F. and Nassar, C.F. (2000): Protective effect of the nitric oxide donor molsidomine on indomethacin and aspirin-induced gastric injury in rats. European journal of gastroenterology and hepatology, 12(1):81-84.

Munzel, T. and Gori, T. (2009): Nebivolol: the somewhat-different beta- adrenergic receptor blocker. Journal of The American College of Cardiology, 54:1491-1499.

Musumba, C.; Pritchard, D.M. and Pirmohamed, M. (2009): Review article: cellular and molecular mechanisms of NSAID-induced peptic ulcers. Alimentary Pharmacology and Therapeutics, 30:517-531.

Nade, V.S.; Shendye, N.V.; Kawale, L.A., et al. (2013): Protective effect of nebivolol on reserpine-induced neurobehavioral and biochemical alterations in rats. Neurochemistry International, 63(4):316-321.

Naito, Y. and Yoshikawa, T. (2006): Oxidative stress involvement and gene expression in indomethacininduced gastropathy. Redox Report: communications in free radical research, 11:243-253.

Nishikimi, M.; Appaji, N. and Yagi, K. (1972): The occurrence of superoxide anion in the reaction of reduced phenazine methosulfate and molecular oxygen. Biochemical and biophysical research communications, 46: 849-854.

Ohkawa, H.; Ohishi, N. and Yagi, K. (1979): Assay for lipid peroxides in animal tissues by thiobarbituric acid reaction. Analytical Biochemistry, 95 (2): 351-358.

Parenti, A.; Filippi, S.; Amerini, S., et al. (2000): Inositol phosphate metabolism and nitric-oxide synthase activity in endothelial cells are involved in the vasorelaxant activity of nebivolol. The Journal of Pharmacology and Experimental Therapeutics, 292:698-703.

Rizzi, E.; Guimaraes, D.A.; Ceron, C.S., et al. (2014): $\beta 1$-Adrenergic blockers exert antioxidant effects, reduce matrix metalloproteinase activity, and improve renovascular hypertension-induced cardiac hypertrophy. Free Radical Biology and Medicine,73:308-317.

Salvemini, D.; Misko, T.P.; Masferrer. J.L., et al. (1993): Nitric oxide activates cyclooxygenase enzymes. Proceedings of the National Academy of Sciences of the United States of America, 90:7240-7244.

Simmons, D.L.; Botting, R.M. and Hla, T. (2004): Cyclooxygenase isozymes: the biology of prostaglandin synthesis and inhibition. Pharmacological reviews, 56:387- 437 . 
Sinha, A.K. (1972): Colorimetric assay of catalase. Analytical Biochemistry, 47: 389-394.

Sinha, K.; Sadhukhan, P.; Saha, S., et al. (2015): Morin protects gastric mucosa from nonsteroidal antiinflammatory drug; indomethacin induced inflammatory damage and apoptosis by modulating NF-kappaB pathway. Biochimica and Biophysica Acta, 1850:769-783.

Sinha, K. and Sil, P.C. (2015): Targeting oxidative stress and inflammation in NSAIDs induced gastropathy: A plausible therapeutic approach. Inflammation \& Cell Signaling, 2: e763.

Slomiany, B.L. and Slomiany, A. (2000): Role of endothelinconverting enzyme-1 in the suppression of constitutive nitric oxide synthase in rat gastric mucosal injury by indomethacin. Scandinavian journal of gastroenterology, 35:1131-1136.

Sorrentino, S.A.; Doerries, C.; Manes, C., et al. (2011): Nebivolol exerts beneficial effects on endothelial function, early endothelial progenitor cells, myocardial neovascilarization and left ventricular dysfunction early after myocardial infarction beyond conventional $\beta 1$ - blockade. Journal of American College of cardiology, 57 (5): 605- 611.

Suleyman, H; Cadirci, E; Albayrak, A; Polat, B, et al. (2009): Comparative study on the gastroprotective potential of some antidepressants in indomethacininduced ulcer in rats. ChemicoBiological Interactions, 180 (2): 318- 324.

Thong-Ngam, D.; Choochuai, S.; Patumraj, S., et al. (2012):
Curcumin prevents indomethacininduced gastropathy in rats. World Journal of Gastroenterology, 18 (13): 1479-1484.

Toblli, J.; Cao, G.; Rivas, C., et al. (2010): Cardiovascular protective effects of nebivolol in Zucker diabetic fatty rats, Journal of Hypertension, 28:1007- 1019.

Uzar, E.; Acar, A.; Evliyaoğlu, O., et al. (2012): The anti-oxidant and anti-apoptotic effects of nebivolol and zofenopril in a model of cerebral ischemia/reperfusion in rats. Progress in Neuropsychopharmacology and Biological Psychiatry, 36: 22-28.

Valcavi, U.; Caponi, R.; Brambilla, A.; Palmira, F. and Fumagali R. (1982): Gastric anti-secretory, antiulcer and cytoprotective properties of 9-hydroxy-19,20-bis-norprostanoic acid in experimental animals. Arzneimittel Forschung, 32 (6): 657-63.

Wallace, J.L. and Miller, M.J. (2000): Nitric oxide in mucosal defense: a little goes along way. Gastroenterology, 119: 512- 520.

Wehland, M.; Grosse, J.; Simonsen, U., et al. (2012): The effects of newer beta-adrenoceptor antagonists on vascular function in cardiovascular disease. Current Vascular Pharmacology, 10:378390.

Whaley-Connell, A.; Habibi, J.; Johnson, M., et al. (2009): Nebivolol reduces proteinuria and renal NADPH oxidase-generated reactive oxygen species in the transgenic Ren2rat. American Journal of Nephrology, 30: 354-360.

Wilcox, C.M. (2006): Gastrointestinal considerations in patients with cardiovascular disease using 
nonopioid analgesics for mild-tomoderate pain or cardioprotection. The American journal of cardiology, 8: 97(9A):17-22.

Wolf, S.C.; Sauter, G.; Jobst, J., et al. (2008): Major differences in gene expression in human coronary smooth muscle cells after nebivolol or metoprolol treatment. International Journal of Cardiology, 125: 4-10.

Yadav, S.K.; Adhikary, B.; Chand, S., et al. (2012): Molecular mechanism of indomethacin-induced gastropathy. Free Radical Biology and Medicine, 52:1175-1187.

Zapater, P.; Gomez-Hurttado, I.; Peiro, G., et al. (2012): Betaadrenergic receptor 1 selective antagonism inhibits noreepinephrine- mediated TNFalpha downregulation in experimental liver cirrhosis. PLoS One, 7(8): e43371.

Zhang, X.; Tajima, K.; Kageyama, K.; Kyoi, T. (2008): Irsogladine maleate suppresses indomethacin-induced elevation of proinflammatory cytokines and gastric injury in rats. World Journal of Gastroenterology, 14: 4784- 4790.

Zhou, X.; Ma, L.; Habibi, J., et al. (2010): Nebivolol improves diastolic dysfunction and myocardial remodeling reductions in oxidative stress in the uccker obese rat. Hypertension, 55: 880- 888. 
الملخص العربي

نيبيفولول يقلل قرحة المعدة المستحثة بواسطة الإندوميثاسين في الجرذان

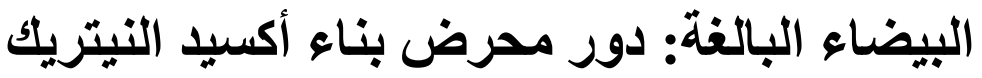

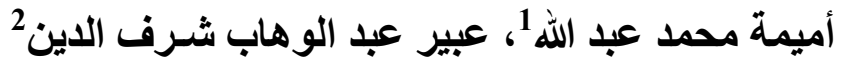

قسم الأدوية والعلاجة، قسم الطب الطبر الثر عي و السموم الإكلينيكية2

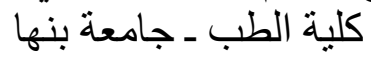

تم دراسة تأثير دواء النبيفولول ،وهو من أدوية الجيل الثالث لمثبطات مستقبلات بيتا-1، على قرحة

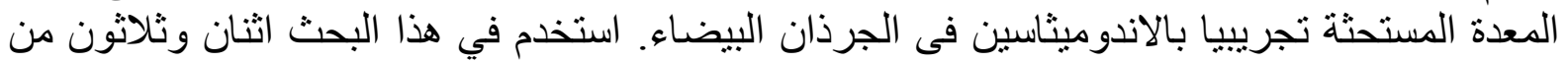

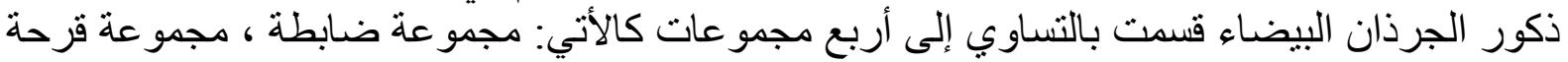

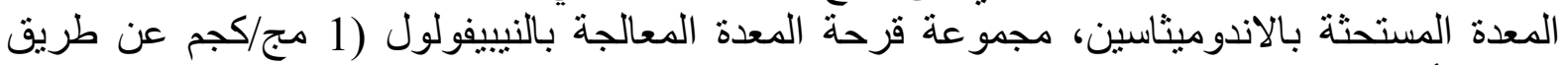

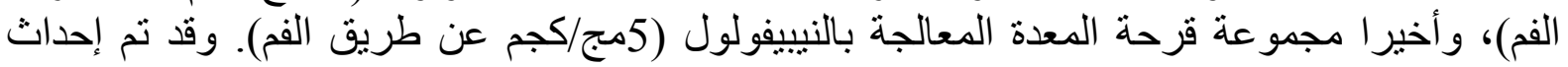

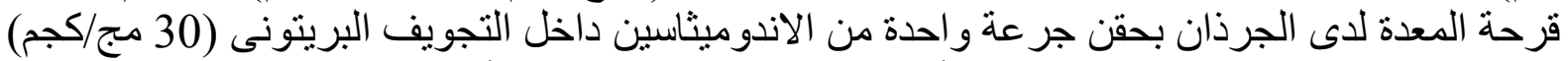

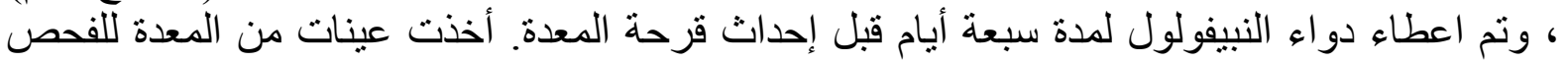

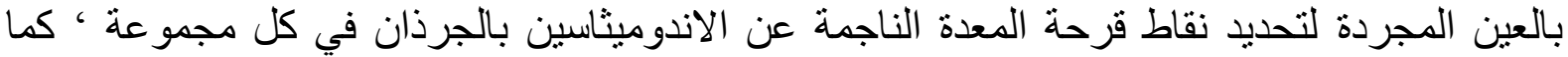

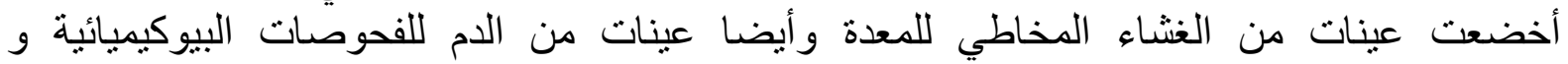

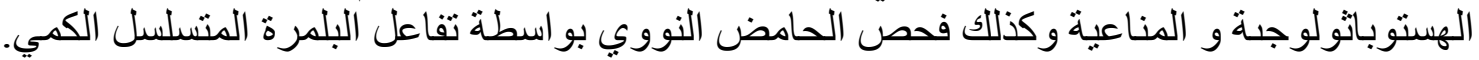

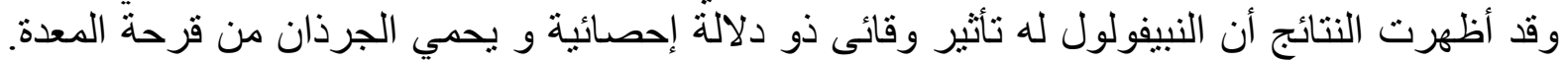

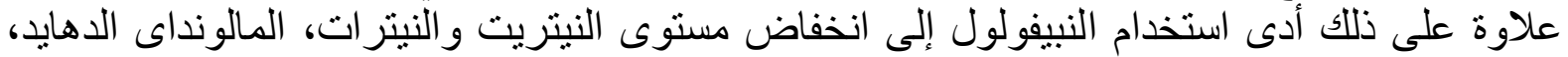

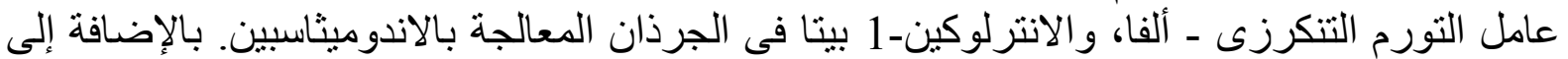

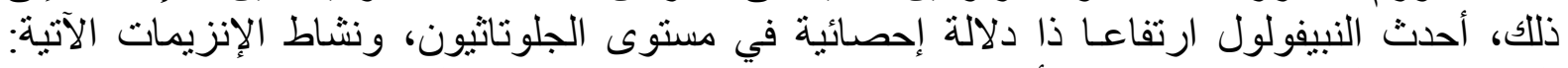

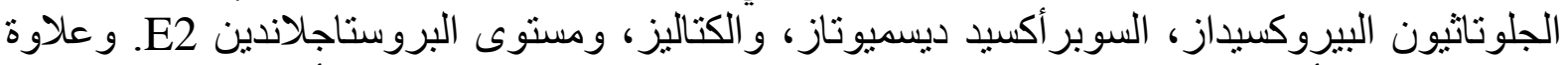

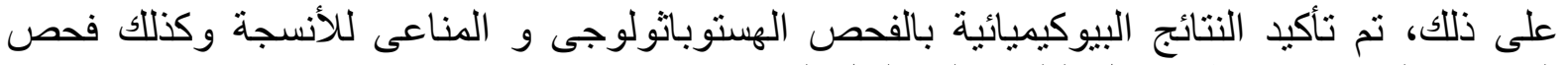

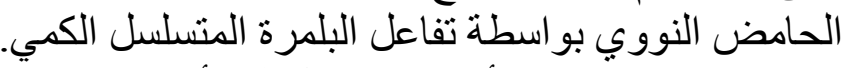

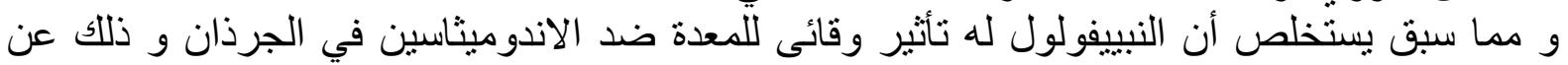

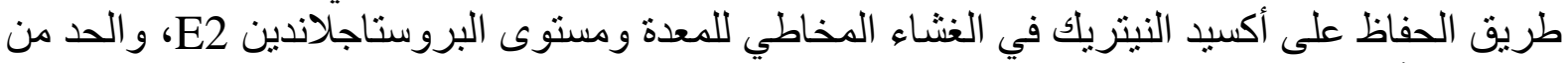
الإجهاد التأكسدي و الاستجابات الالتهابية. 